\title{
Penyuluhan Dan Sosialisasi Perda Kota Makassar No 7 Tahun 2009
}

\author{
St. Hatidja ${ }^{1}$, Apiaty K Amin ${ }^{2}$, Lina Mariana ${ }^{3}$,Salmiyah Thaha ${ }^{4}$ \\ ${ }^{1}$ Pasca STIE Amkop, ${ }^{2}$ Universitas Pepabri, ${ }^{3}$ Politeknik LP3I Makassar, ${ }^{4}$ STIE Tri Dharma \\ Nusantara \\ Email : hatidja@stieamkop.ac.id, syamaty31@gmail.com, linamariana5390@gmail.com, \\ mia.thaha@stie-tdn.ac.id
}

\begin{abstract}
The purpose of community service activities is to provide education and information to the people of the city of Makassar specifically in Ujung Pandang, Makassar and Rappocini sub-districts. The people of Makassar city in general are still not aware of local regulations regarding health services. Most residents of Makassar city complain about health services in the city of Makassar. And some residents only know about health services through BPJS and KIS (Healthy Indonesia Card). So it is necessary for the government to cooperate with related parties to conduct socialization and counseling of Regional Regulations regarding health services. The result of PKM activities is that participants know the regional regulation number 7 of 2009, participants are able to socialize to their environment about the regulation.
\end{abstract}

Keywords: Counseling, Makassar City Health Services

\begin{abstract}
Abstrak
Tujuan kegiatan pengabdian masyarakat adalah untuk memberikan edukasi dan informasi kepada masyarakat kota Makassar khususnya kecamatan Ujung Pandang, Kecamatan Makassar dan Kecamatan Rappocini. Masyarakat kota Makassar pada umumnya masih kurang mengetahui peraturan daerah tentang pelayanan kesehatan. Sebagian besar warga kota Makassar mengeluhkan pelayanan kesehatan di kota Makassar. Dan sebagian warga hanya mengetahui pelayanan kesehatan melalui BPJS maupun KIS (Kartu Indonesia Sehat). Sehingga perlunya pihak pemerintah bekerjasama dengan pihak terkait untuk melakukan sosialisasi dan penyuluhan Perda mengenai pelayanan kesehatan. Hasil kegiatan PKM adalah peserta mengetahui perda nomor 7 tahun 2009, peserta mampu mensosialisasikan ke lingkungan mereka tentang perda tersebut.
\end{abstract}

Kata kunci : Penyuluhan, Pelayanan Kesehatan Kota Makassar

\section{Pendahuluan}

Tugas pokok birokrasi pemerintah adalah memberikan pelayanan publik. Salah satu bagian dari pelayanan publik yakni Pelayanan Kesehatan. Kesehatan merupakan salah satu kebutuhan dasar masyarakat, oleh karena itu kesehatan merupakan hak setiap warga negara yang dilindungi secara konstitusional. Setiap negara sepakat bahwa kesehatan adalah aset terbesar dalam mencapai kemakmuran. Oleh karena itu, peningkatan pelayanan kesehatan pada dasarnya merupakan investasi sumber daya manusia untuk mewujudkan masyarakat yang sejahtera. (welfare society).

Undang-Undang Nomor 23 Tahun 1992 Tentang Kesehatan Pasal 3 menyebutkan bahwa Pembangunan kesehatan bertujuan untuk meningkatkan kesadaran, kemauan dan kemampuan hidup sehat bagi setiap orang agar terwujud derajat kesehatan masyarakat yang optimal .Tujuan pembangunan kesehatan itu sendiri adalah untuk meningkatkan kesadaran, kemauan dan kemampuan hidup sehat bagi semua orang, untuk mencapai derajat kesehatan dan gizi yang optimal melalui terciptanya lingkungan hidup yang sehat bermasyarakat, berbangsa dan bernegara Indonesia, kesempatan memperoleh pelayanan 
kesehatan yang bermutu secara adil dan merata serta melalui kualifikasi kesehatan yang optimal di seluruh Indonesia.

Undang-Undang Nomor 36 Tahun 2009 Pasal 5 Tentang Kesehatan, telah ditetapkan bahwa "setiap individu, keluarga dan masyarakat mempunyai hak yang sama dalam memperoleh akses atas sumber daya di bidang kesehatan serta mempunyai hak dalam memperoleh pelayanan kesehatan yang aman, bermutu, dan terjangkau."

Kesehatan masyarakat merupakan hak asasi manusia yang harus di hormati oleh Negara. Pemerintah perlu menerapkan prinsip-prinsip good governance dalam penyelenggaraan pelayanan public, termasuk pelayanan kesehatan. Peran serta warga masyarakat untuk memelihara diri,lingkungan dan masyarakat sangatlah penting. Artinya, menjaga kesehatan diri sendiri, masyarakat dan lingkungan merupakan kunci utama untuk mencapai kesehatan secara umum.

Tujuan dari PKM adalah untuk memberikan edukasi dan informasi kepada masyarakat kota Makassar khusus kecamatan Ujung Pandang, Kecamatan Makassar dan Kecamatan Rappocini. "Penanganan Covid-19 di Kota Makassar dinilai masih rendah termasuk dalam hal tracing. Oleh karena itu, Pemerintah Kota Makassar telah mengumpulkan seluruh Kepala Puskesmas untuk mengevaluasi pelayanan kesehatan.” (FajarNews, 2021)

Pemerintah kota Makassar perlu memberikan pemahaman dan edukasi secara terus menerus kepada warganya mengenai kesehatan dan pentingnya kesehatan. Apalagi di masa pandemic Covid 19, peran serta pemerintah sangat diperlukan dalam pemberikan penyuluhan dan sosialisasi mengenai pentingnya menjaga kesehatan.

Selain menjaga kesehatan, tentu pemerintah kota Makassar juga memberikan edukasi dan informasi kepada warganya mengenai pelayanan kesehatan yang berhak di peroleh warganya. Pemberian edukasi dan informasi dilakukan melalui kegiatan sosialisasi dan penyuluhan.

Berdasarkan Perda Kota Makassar Nomor 7 tahun 2009 pasal 1 dikatakan bahwa "Pelayanan kesehatan adalah segala kegiatan yang diberikan kepada seseorang dalam rangka observasi, diagnosis, pengobatan atau pelayanan kesehatan lainnya di Rumah Sakit Umum Daerah, Pusat Kesehatan Masyarakat (Puskesmas) dan jaringannya”.

Pelayanan kesehatan kota Makassar di atur dalam Perda Nomor 7 tahun 2009 tentang Pelayanan Kesehatan di Kota Makassar.

\section{a. Pelayanan Publik}

Menurut (Sedarmayanti, 2010) pelayanan berarti memberikan jasa sesuai yang dibutuhkan oleh masyarakat dalam segala bidang. Memberikan pelayanan kepada masyarakat merupakan tugas dan fungsi dari penyelenggaraan Negara.

Menurut Sedarmayanti (2009) yang dikutip oleh (Siswanto et al., 1821) kualitas pelayanan merujuk pada pengertian:

1) Kualitas merupakan bagian dari keistimewaan produk, baik langsung maupun atraktif untuk memenuhi keinginan dan memberikan kepuasan atas produk yang digunakan.

2) Kualitas artinya bebas dari kerusakan/kekurangan.

b. Pelayanan Kesehatan

Dalam pasal 30 UU No. 36 Tahun 2009 yang membahas tentang Kesehatan dan Peraturan Presiden No. 72 Tahun 2012 tentang Sistem Kesehatan Nasional $(\mathrm{SKN})$, Indonesia menganut sistem pelayanan kesehatan berjenjang yang terbagi menjadi 3 jenjang, yaitu pelayanan tingkat pertama atau primer, tingkat kedua atau sekunder, dan tingkat ketiga atau tersier. Di setiap tingkatan layanan 
tersebut, terbagi menjadi 2 upaya pelayanan kesehatan yaitu upaya kesehatan masyarakat (UKM) dan upaya kesehatan perorangan (UKP). Semua fasilitas layanan tersebut dapat diselenggarakan oleh pemerintah, pemerintah daerah, masyarakat, dan swasta.

Pelayanan kesehatan didalamnya terdiri dari peningkatan, pencegahan, pengobatan, dan pemulihan, baik pelayanan kesehatan konvensional maupun pelayanan kesehatan tradisional, alternatif dan komplementer.(Manajemen Pelayanan Kesehatan " BAB III - Upaya Kesehatan, n.d.)

Pelayanan kesehatan meliputi pelayanan kesehatan tingkat pertama/primer, pelayanan kesehatan tingkat kedua/sekunder dan pelayanan kesehatan tingkat ketiga/tersier.

Dengan meningkatnya tingkat pendidikan dan keadaan sosial ekonomi masyarakat, maka kebutuhan dan tuntutan masyarakat akan kesehatan semakin meningkat sehingga tidak ada lagi upaya yang dapat dilakukan selain meningkatkan kinerja petugas kesehatan dan menyelenggarakan pelayanan Kesehatan dengan sebaik- baiknya. (Nopiani, 2019)

\section{Metode Pelaksanaan PKM}

Kegiatan PKM ini dilakukan dengan beberapa tahapan, yaitu :

1. Tahap Sosialisasi

Pada tahap ini dilakukan sosialisasi Perda Nomor 7 tahun 2009 tentang pelayanan kesehatan di Kota Makassar kepada para peserta.

2. Penyusunan Metode Kegiatan

Pada tahap ini, TIM PKM terlebih dahulu melakukan survey apakah masyarakat di kecamatan Ujung Pandang, Kecamatan Makassar dan Kecamatan Rappocini telah mengetahui Perda Kota Makassar Nomor 7 tahun 2009 tentang Pelayanan Kesehatan. Metode yang di gunakan adalah dengan metode kuisioner dengan menggunakan sample kurang lebih 100 warga.

3. Tahap Pelaksanaan

Sebelum pelaksanaan kegiatan dilakukan, terlebih dahulu dilakukan kontrak dengan mitra untuk membuat kesepakatan mengenai tempat dan waktu pelaksanaan. Kontrak dilakukan dengan tujuan agar kegiatan PKM dapat berjalan dengan baik dan lancar. Antara calon peserta dan tim pelaksana bisa bekrjasama hingga waktu kegiatan selesai. Metode yang dilaksanakan pada kegiatan adalah penyuluhan dan sosialisasi.

4. Monitoring dan Evaluasi

Agar tujuan kegiatan PKM tercapai, maka seluruh bentuk kegiatan yang dilaksanakan akan dipantau secara berlanjut untuk melihat kesesuaiannya dengan rencana yang telah disusun. Adapun spesifikasi kegiatan monitoring yang dilakukan adalah:

a. Peserta

Monitoring peserta dilakukan melalaui absensi peserta dan kehadiran peserta sejak kegiatan di mulai hingga kegiatan berakhir.

b. Keaktifan peserta

Keaktifan peserta dilihat dari tanggapan dan pertanyaan yang diberikan oleh peserta terkait materi yang di sampaikan.

c. Kemampuan peserta menerima materi 
Dilakukan dengan memberi kesempatan kepada peserta untuk mempersentasikan kembali materi yang telah di sampaikan.

Kegiatan evaluasi dilakukan sebanyak dua kali, yang pertama evaluasi yang dilaksanakan setiap kegiatan selesai atau program berakhir. Pada tahap ini, evaluasi bertujuan untuk melihat efektifitas dan efisiensi program kegiatan, serta melihat kendala yang ditemui selama program berlangsung. Evaluasi tahap berikutnya adalah evaluasi untuk melihat hasil capaian dari program kegiatan, sekaligus menjadi bahan penyusunan laporan akhir kegiatan.

\section{Hasil dan Pembahasan}

Pemberian materi dimulai dengan sosialisasi Peraturan daerah Kota Makassar Nomor 7 tahun 2009 mengenai pelayanan kesehatan oleh narasumber. Pemaparan perda bertujuan untuk memberikan informasi kepada para peserta mengenai jenis-jenis pelayanan kesehatan yang berhak di dapatkan bagi warga di kota Makassar. Pada tahap sosialisasi juga di paparkan bahwa Pemerintah Kota memberikan pelayanan kesehatan kepada masyarakat pada RSUD, Puskesmas dan jaringannya, baik Penduduk Kota maupun Penduduk Luar Kota. Para peserta juga memperoleh materi berupa Peraturan daerah Nomor 7 tahun 2009 tentang pelayanan kesehatan. Sosialisasi ini juga di harapkan agar para peserta yang hadir, menjadi perwakilan untuk memberikan informasi tersebut ke masyarakat di sekitar lingkungan peserta tinggal.

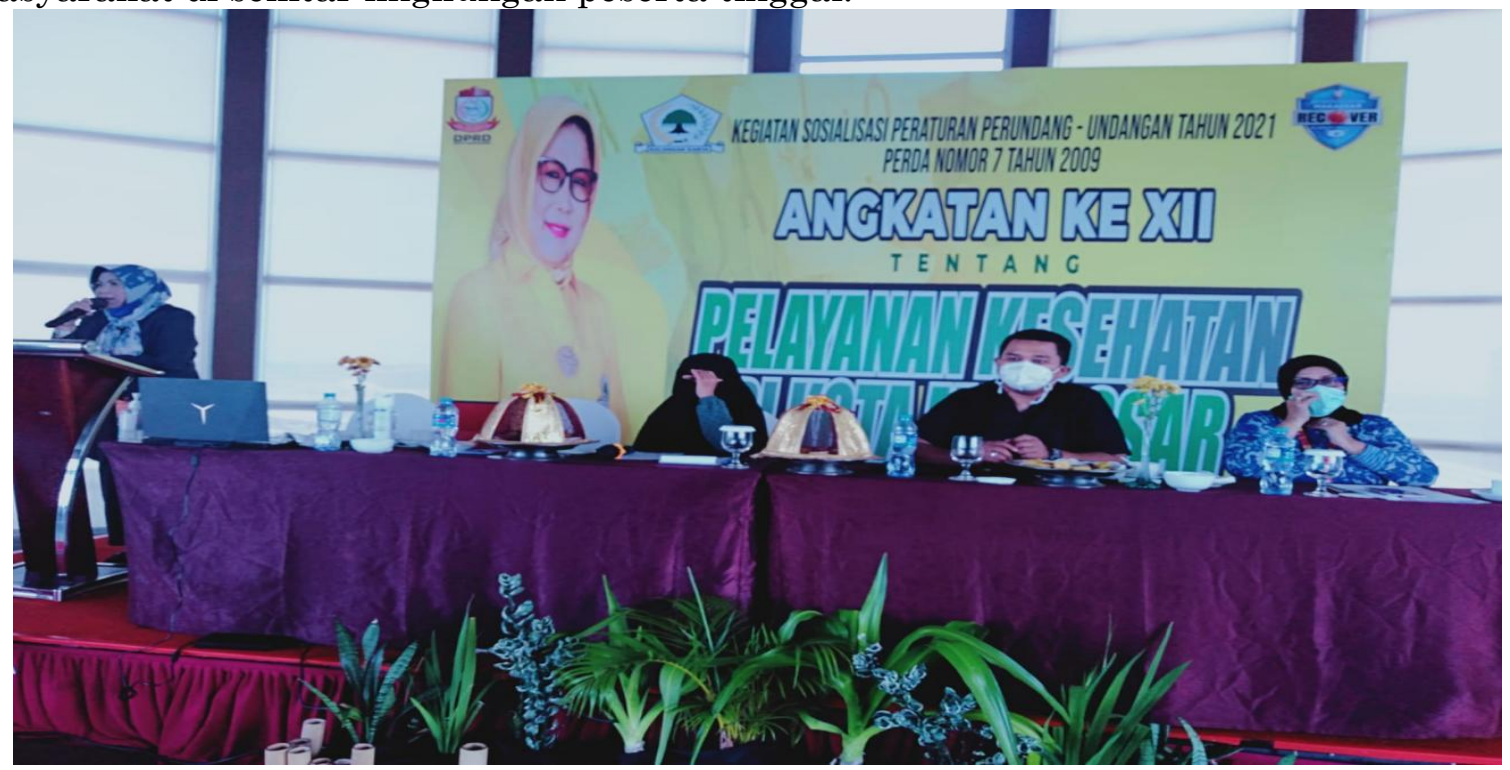

Gambar 1. Sosialisasi Perda No 7 Tahun 2009 Oleh Narasumber

Pada tahap sosialisasi Perda Nomor 7 tahun 2009 yang dipaparkan oleh narasumber, tim PKM berharap para peserta memahami peraturan perundang-undangan yang mengatur mengenai pelayanan kesehatan yang bisa di dapatkan oleh warga masyarakat kota Makassar dan mengerti bahwa ada sangsi bagi penyedia jasa pelayanan kesehatan yang melanggar. Warga masyarakat diharapkan tidak ragu-ragu lagi untuk memeriksakan diri ke tempat pelayanan kesehatan yang telah disediakan oleh pemerintah kota Makassar. Karena pada saat ini banyak warga kota Makassar yang takut memeriksakan 
diri ke Rumah Sakit atau Puskesmas terdekat karena berbagai alasan. Ada yang khawatir karena harus membayar banyak, ada yang khawatir karena takut di covid kan dan ada pula yang masih tidak tahu Rumah sakit yang mana yang menjadi rumah sakit milik pemerintah.

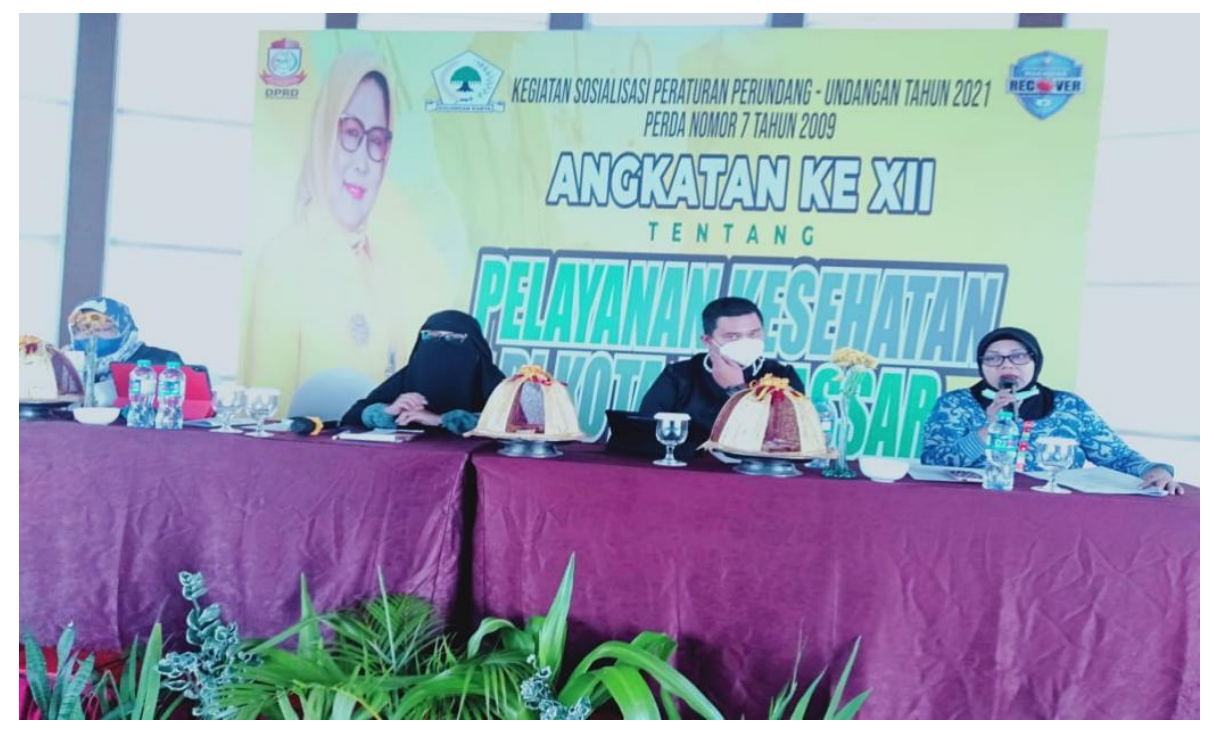

Gambar 2. Pemaparan Materi Oleh Narasumber

Metode diskusi dilakukan untuk mengidentifikasi masalah yang dihadapi warga masyarakat terkait pelayanan kesehatan. Dari hasil diskusi ditemukan beberapa masalah yaitu:

1. Peserta yang hadir mayoritas belum mengetahui Perda nomor 7 tahun 2009.

2. Adanya warga mengeluh soal pelayanan kesehatan di Makassar.

3. Ada warga yang masih bingung mengenai pelayanan BPJS dan KIS

4. Masih banyak warga yang khawatir memeriksakan diri ke rumah sakit atau puskesmas karena takut biaya mahal dan khawatir di nyatakan positif Covid 19.

5. Masih ada warga yang tidak mengetahui mengenai biaya-biaya pelayanan kesehatan di kota Makassar.

Melalui diskusi para peserta sangat antusias mengajukan pertanyaan mengenai pelayanan kesehatan selama pandemic. 


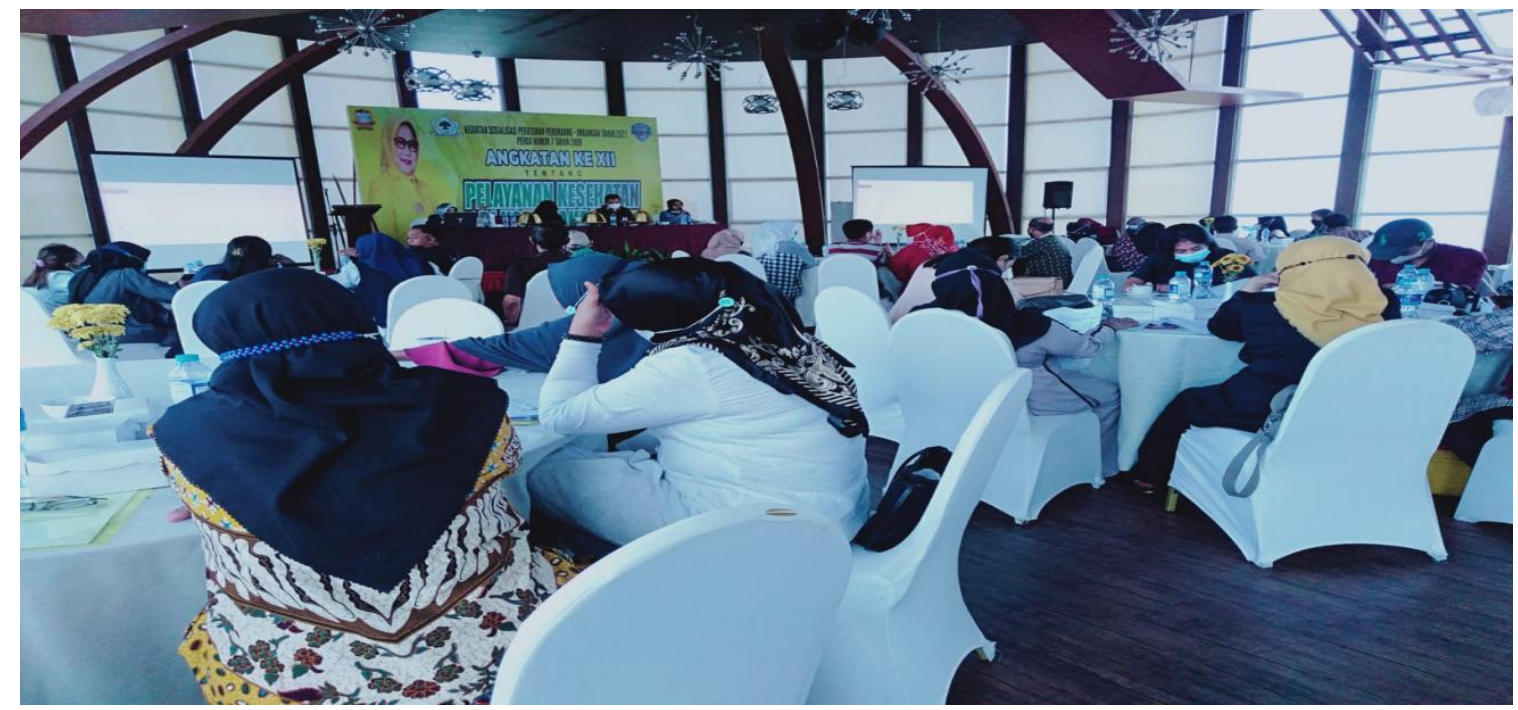

Gambar 3. Penyuluhan Kesehatan Oleh Narasumber

\section{Kesimpulan}

Dari kegiatan PKM dapat disimpulkan bahwa terdapat peningkatan pengetahuan peserta terhadap perda Nomor 7 tahun 2009. Terdapat peningkatan pengetahuan peserta mengenai cara menjaga kesehatan dan pelayanan kesehatan selama pandemic.Peserta mengetahui perbedaan antara penggunaan manfaat BPJS dan KIS.

Saran TIM demi perbaikan selanjutnya adalah :

1. Perlunya ada sosialisasi secara berkelanjutan mengenai perda tentang pelayanan kesehatan.

2. Perlu adanya penyuluhan pelayanan kesehatan kepada masyarakat secara berkelanjutan.

\section{UCAPAN TERIMA KASIH}

Melalui media ini, tim PKM mengucapkan terimakasih kepada Dewan Perwakilan Rakyat Kota Makassar atas kepercayaannya kepada tim kerjasama dan fasilitas yang telah diberikan.

\section{Daftar Pustaka}

Azwar, Asrul. (1994). Manajemen Kualitas Pelayanan Kesehatan. Pustaka Sinar Harapan. Jakarta

FajarNews. (2021). Penanganan COVID-19 di Kota Makassar Dinilai Masih Rendah. https://fajar.co.id/2021/08/10/penanganan-covid-19-di-kota-makassar-dinilai-masihrendah/

Manajemen Pelayanan Kesehatan" BAB III - Upaya Kesehatan. (n.d.). Retrieved September 11, 2021, from http://manajemen-pelayanankesehatan.net/petunjuk-teknispelayanan-kesehatan-provinsi-riau/bab-iii-upaya-kesehatan/

Nopiani, C. S. (2019). Pelayanan Kesehatan Masyarakat Di Puskesmas Simpang Tiga Kecamatan Banyuke Hulu Kabupaten Landak. Jurnal Ilmu Manajemen Dan Akuntansi, 7(1), 1-7. 
ABDINE: Jurnal Pengabdian Kepada Masyarakat Vol.1, No.2, Desember 2021, Hal. 110-116

p-ISSN 2798-2882, e-ISSN 2798-2890

Peraturan Daerah kota Makassar No. 7 Tahun 2009 tentang pelayanan kesehatan Peraturan Presiden No. 72 Tahun 2012 tentang Sistem Kesehatan Nasional Republik Indonesia. Undang-Undang Nomor 23 Tahun 1992 tentang kesehatan Republik Indonesia. Undang-Undang Nomor 36 Tahun 2009 tentang kesehatan Sedarmayanti. (2010). Reformasi Administrasi Publik, Reformasi Birokrasi, Dan Kepemimpinan Masa Depan (Mewujudkan Pelayanan Prima dan Kepemerintahan Yang Baik) (Cetakan ke). Refika Aditama.

Siswanto, H., Makmur, M., \& Lastiti, N. (1821). Analisis Kualitas Pelayanan Kesehatan Dalam Operasionalisasi Program Mobil Sehat (Studi Pada Pusat Kesehatan Masyarakat Kedungpring Kabupaten Lamongan). JAP, 3(11). 